Article

\title{
Bidirectional DC Converter with Frequency Control: Analysis and Implementation
}

\author{
Bor-Ren Lin *(i) and Yen-Chieh Huang \\ Department of Electrical Engineering, National Yunlin University of Science and Technology, \\ Yunlin 640, Taiwan; m10512048@yuntech.edu.tw \\ * Correspondence: linbr@yuntech.edu.tw; Tel.: +886-912312281
}

Received: 18 August 2018; Accepted: 13 September 2018; Published: 14 September 2018

check for updates

\begin{abstract}
In this paper, a direct current (dc) converter with the abilities of bidirectional power transfer and soft switching characteristics is studied and implemented. The circuit schematic of the developed dc converter is built by a half-bridge converter and a center-tapped rectifier with synchronous rectifier. Under forward power transfer, a half-bridge circuit is controlled to regulate the low-voltage side at a stable value. For backward power transfer, a center-tapped rectifier with synchronous rectifier is regulated to control the high-voltage side at the desired voltage value, and the half-bridge circuit is operated as a voltage doubler rectifier. Active power devices are operated at zero-voltage switching using a series resonant technique on the high-voltage side with frequency modulation and inductive load operation. The practicability of the developed converter is established from experiments with a laboratory prototype circuit.
\end{abstract}

Keywords: dc-dc converter; bidirectional power control; soft switching

\section{Introduction}

To reduce air pollution and climate change, renewable energy sources with power electronic conversion have been demanded and developed in recent years. Bidirectional power converters [1-18] have been developed for alternating current (ac) to direct current (dc) conversion and dc-dc conversion. In references [1-7], ac-dc bidirectional power converters are employed between an ac power source and dc bus voltage, and dc-ac bidirectional power converters are widely employed in ac drive systems. Direct current to dc bidirectional power converters [8-13] are demanded for battery-based storage systems. Bidirectional power flow dc converters with dual full-bridge circuit topology or half-bridge circuit topology were proposed to deliver power between high-voltage side dc bus and low-voltage side storage devices. Duty cycle control is normally used in dual full-bridge converters to control load voltage and attain soft switching characteristics. The main drawbacks of dual full-bridge converters are complicated control scheme and high conduction losses under low effective duty cycle case with high circulating current. Resonant techniques with a frequency-control scheme have been developed in modern power converters with high circuit efficiency due to wide load range of soft switching characteristics. The dual full-bridge resonant converter in reference [14] achieves soft switching characteristics in forward power transfer. However, the soft switching characteristics were lost in this circuit topology in backward power transfer due to the non-symmetric circuits in both power flow operations. The circuit topologies of dual full-bridge resonant converters in references [15-17] are symmetric for both forward and backward power transfer. Therefore, active switches can achieve soft switching at turn-on instant to eliminate switching loss. However, one parallel inductor is used on the high-voltage side. The circulating current in this parallel inductor will result in additional power loss when the circuit is operated under forward power transfer.

A soft switching resonant converter is studied and implemented in this paper to have the benefits of bidirectional power transfer ability, soft switching characteristics and less power devices. 
The proposed circuit is constructed by a half-bridge circuit on the primary-side and a center-tapped rectifier on the secondary-side. The LLC resonant circuit with frequency control is used on high-voltage side to control secondary-side voltage, reach soft switching turn-on for main power devices. To achieve same LLC resonant characteristics for both forward and backward power transfer, a parallel inductor is connected between half-bridge leg and split input capacitors on the high-voltage side. Under forward power transfer, power switches on half-bridge circuit are controlled by frequency-modulation to generate a square voltage input to the resonant tank and regulate low-side voltage $V_{L}$. Power switches on a center-tapped rectifier with synchronous switches are operated as synchronous rectifiers for reducing the conduction losses on the low-voltage side. Under forward power flow, the parallel inductor on the high-voltage side is disconnected (ac power switch is off) to reduce the power loss on this parallel inductor. When the proposed circuit is worked under backward power transfer, the parallel inductor is used on the high-voltage side to achieve LLC resonant characteristics. Power switches on the center-tapped rectifier are controlled to create a square voltage waveform on the primary-side of the isolated transformer and regulate high-side voltage $V_{H}$. Finally, experimental results are presented to verify the feasibility of the proposed circuit.

\section{Circuit Diagram}

Figure 1a shows the circuit schematic of a conventional resonant converter with s center-tapped rectifier on the secondary side. The main drawback in Figure 1a is high conduction loss on secondary-side rectifier diodes for high current output. In order to reduce conduction loss on secondary-side diodes, synchronous switches instead of fast recovery diodes are used on the secondary-side as shown in Figure 1b. For achieving bidirectional power control, Figure 2a demonstrates the circuit structure of the developed bidirectional dc converter. The circuit differences between the proposed converter and conventional unidirectional half-bridge resonant converter shown in Figure $1 \mathrm{~b}$ are one ac switch $S$ and inductor $L_{m} 1$ used in the proposed circuit to achieve LLC resonant behavior for both forward and backward power transfer. Therefore, the advantages of a conventional unidirectional LLC resonant converter all exist in the proposed circuit. Half-bridge circuit is employed on the high voltage side to clamp voltage ratings of power semiconductor devices $Q_{1}$ and $Q_{2}$ at $V_{H}$. A center-tapped circuit topology with synchronous rectifier is employed on the secondary-side to reduce the conduction loss on the low-voltage side. An ac switch $S$ is adopted on the primary-side to achieve resonant behavior when the adopted circuit is operated at backward power transfer. Figure $2 \mathrm{~b}$ demonstrates the equivalent circuit of the developed circuit operated at forward power transfer from $V_{H}$ to $V_{L}$. AC switch $S$ is turned off. $C_{r}, L_{r}$ and $L_{m 2}$ are operated to achieve soft switching turn-on of $Q_{1}$ and $Q_{2}$. Power devices $Q_{3}$ and $Q_{4}$ on the low-voltage side operate as the synchronous switches. Therefore, the conduction losses on $Q_{3}$ and $Q_{4}$ are reduced at the low-voltage and high-current sides. Figure 2c illustrates circuit structure of the studied circuit operated at backward power transfer from $V_{L}$ to $V_{H}$. At backward power transfer condition, power switch $S$ is closed and $Q_{1}$ and $Q_{2}$ are turned off. $L_{m 1}, C_{r}$ and $L_{r}$ are resonant. Thus, main switches $Q_{3}$ and $Q_{4}$ are turned on under zero-voltage switching. Table 1 gives the basic comparison between the proposed circuit and the conventional bidirectional dc-dc converters. It can be observed that the proposed converter has less component counts.

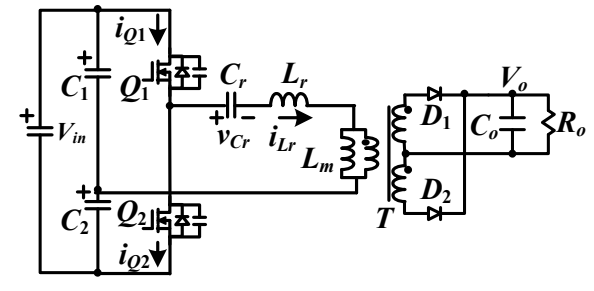

(a)

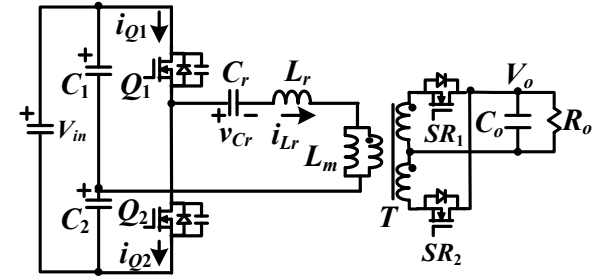

(b)

Figure 1. Circuit diagram of conventional resonant converter with (a) center-tapped rectifier on the secondary-side $(\mathbf{b})$ with synchronous rectifier on the secondary-side. 


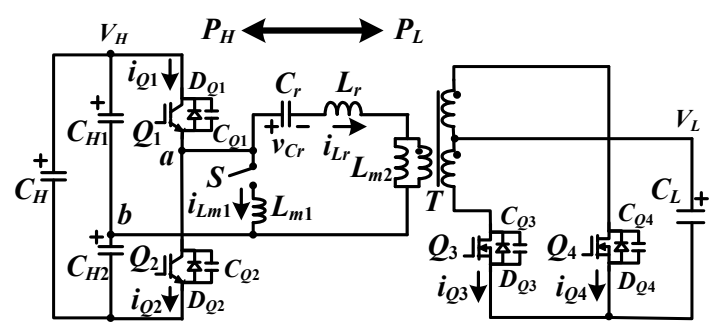

(a)

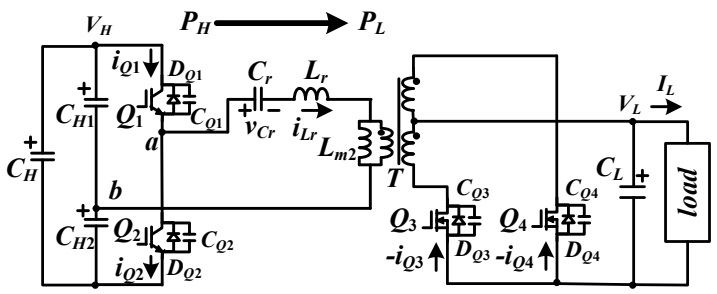

(b)

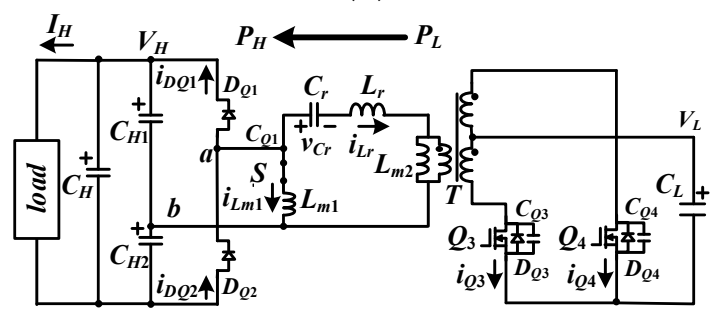

(c)

Figure 2. Proposed circuit (a) circuit diagram (b) forward power transfer (c) reverse power transfer.

Table 1. Circuit topologies and component counts between the proposed converter and the other bidirectional dc-dc converters.

\begin{tabular}{|c|c|c|c|c|}
\hline & Primary-Side & Secondary-Side & Component Counts & Control Scheme \\
\hline Proposed converter & Half-bridge circuit & Center-tapped circuit & $\begin{array}{c}5 \text { switches, } 3 \text { magnetic components, } \\
1 \text { resonant capacitor }\end{array}$ & Frequency control \\
\hline $\begin{array}{l}\text { Circuit topology in } \\
\text { Reference [8] }\end{array}$ & Full-bridge circuit & Center-tapped circuit & 6 switches, 2 magnetic components & Duty cycle control \\
\hline $\begin{array}{l}\text { Circuit topology in } \\
\text { Reference [9] }\end{array}$ & Full-bridge circuit & Full-bridge circuit & 8 switches, 2 magnetic components & Duty cycle control \\
\hline $\begin{array}{l}\text { Circuit topology in } \\
\text { Reference [10] }\end{array}$ & Half-bridge circuit & Half-bridge circuit & $\begin{array}{c}6 \text { switches, } 3 \text { magnetic components, } \\
1 \text { resonant capacitor }\end{array}$ & Frequency control \\
\hline $\begin{array}{l}\text { Circuit topology in } \\
\text { Reference [14] }\end{array}$ & Full-bridge circuit & Full-bridge circuit & $\begin{array}{c}8 \text { switches, } 2 \text { magnetic components, } \\
1 \text { resonant capacitor }\end{array}$ & Frequency control \\
\hline $\begin{array}{l}\text { Circuit topology in } \\
\text { Reference [16] }\end{array}$ & Full-bridge circuit & Full-bridge circuit & $\begin{array}{c}8 \text { switches, } 3 \text { magnetic components, } \\
2 \text { resonant capacitors }\end{array}$ & Frequency control \\
\hline
\end{tabular}

\section{Principles of Operation}

\subsection{Forward Power Flow}

If the converter is operated at forward power transfer as shown in Figure 2a, the power flow is from $V_{H}$ terminal to $V_{L}$ terminal. Power device $S$ is controlled at the OFF state. Power switches $Q_{1}$ and $Q_{2}$ are regulated with frequency control to create a square voltage $v_{a b}$ on the high-voltage side. Power switches $Q_{3}$ and $Q_{4}$ are operated as the synchronous switches to decrease conduction loss compared to the rectifier diodes with high voltage drop when diodes are conducting. The ON/OFF state of the synchronous switches are based on the current direction on the low-voltage side. Then a square voltage waveform can be created on the primary-side of the isolated transformer. $L_{m 2}, L_{r}$ and $C_{r}$ are the magnetizing inductance, series resonant inductance and series resonant capacitance, respectively. Due to the inductive impedance of the resonant tank on the high-voltage side, as shown in Figure 3a, the soft switching characteristics of main switches $Q_{1}$ and $Q_{2}$ are achieved. The basic pulse-width 
modulation signals for forward power transfer operation are illustrated in Figure 3a. There are six operation modes under $f_{r}$ (series resonant frequency) $>f_{s w}$ (switching frequency). On the other hand, four operation modes per switching cycle can be observed if $f_{s w}>f_{r}$. Figure 4 illustrates the equivalent topological circuits for each mode of operation under forward power transfer. The principles of operation are discussed in what follows.
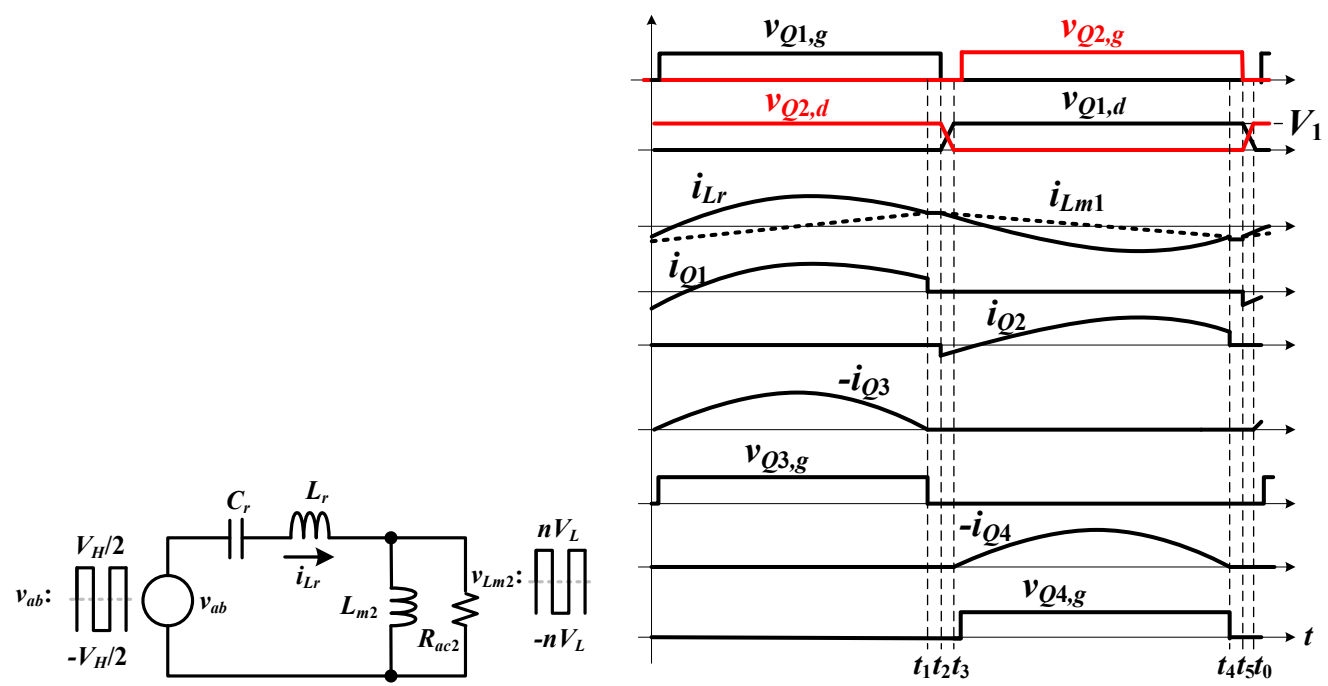

(a)
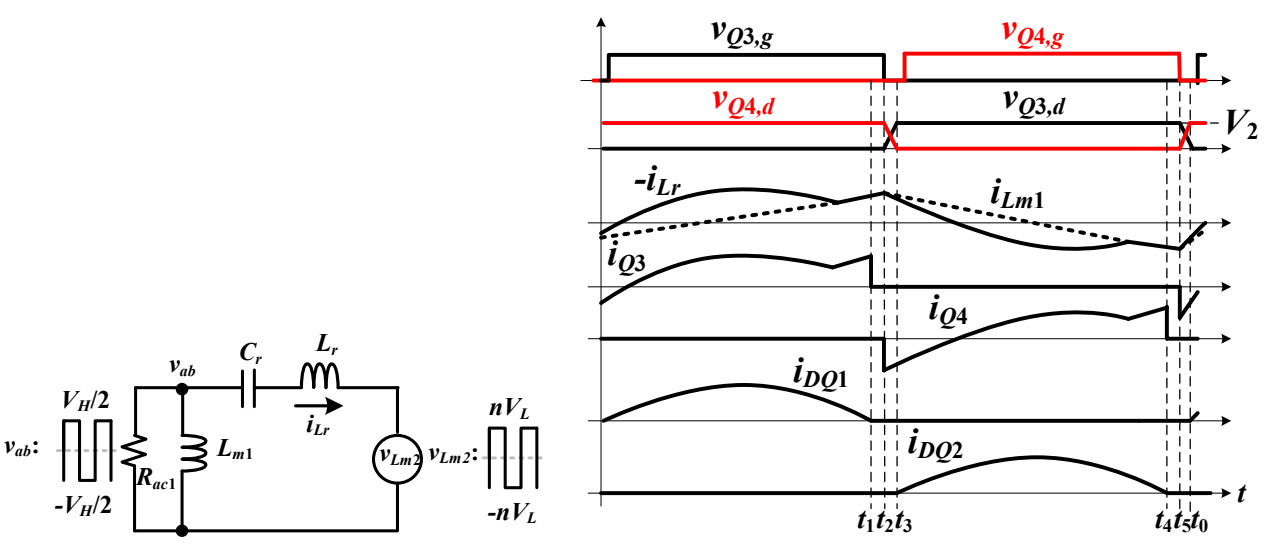

(b)

Figure 3. Resonant tank of the studied circuit (a) forward power transfer from $V_{H}$ to $V_{L}$ (b) backward power transfer from $V_{L}$ to $V_{H}$.

Mode $1\left[t_{0} \sim t_{1}\right]$ : At $t_{0}, v_{C Q 1}=0$. Since $i_{Q 1}\left(t_{0}\right)<0, D_{Q 1}$ conducts. Thus, $Q_{1}$ is turned on under zero voltage after $t_{0}$. In mode $1, i_{L r}>i_{L m 2}$ so that $i_{Q 3}<0$ and $D_{Q 3}$ conducts. Thus, $Q_{3}$ is forced to turn on. Due to low turn-on resistance $R_{o n}$, the conduction losses on $Q_{3}$ are reduced. In this mode, the voltage $v_{a b}=V_{C H 1}=V_{H} / 2$ and $v_{L m 2}=n V_{L}$. The magnetizing current $i_{L m 2}$ will increase with the current slope $n V_{L} / L_{m 2}$. In mode 1 , the current variation on $L_{m 2}$ is calculated as $\Delta i_{L m 2,1}=n V_{L} \Delta t_{10} / L_{m 2}$ where $\Delta t_{10}$ is time duration in this mode. $C_{r}$ and $L_{r}$ are resonant under $v_{a b}=V_{H} / 2, v_{L m 2}=n V_{L}$ and the series resonant frequency $f_{r}=1 / 2 \pi \sqrt{C_{r} L_{r}}$. If $f_{r}>f_{s w}$, then $i_{D Q 3}$ will fall to zero. Thus, the next mode will go to mode 2. On the other hand, the circuit operation will go to mode 3 if $f_{r}<f_{s w}$.

Mode $2\left[t_{1} \sim t_{2}\right.$ ]: At time $t_{1}, i_{Q 3}$ falls to zero. Then $Q_{3}$ is forced to turn off. $i_{L r}$ will flow through $Q_{1}, C_{r}$, $L_{r}, L_{m 2}$ and $C_{H 1}$. Due to $C_{H 1}>C_{r}, L_{r}, C_{r}$ and $L_{m 2}$ are resonant in mode 2 with $v_{a b}=V_{H} / 2$ and resonant frequency $f_{p}=1 / 2 \pi \sqrt{C_{r}\left(L_{r}+L_{m 2}\right)}$. Mode 2 ends at the half of the switching frequency $t=T_{s w} / 2$. 
Mode $3\left[t_{2} \sim t_{3}\right]$ : At time $t_{2}, Q_{1}$ turns off and $i_{L r}\left(t_{2}\right)>0$. After time $t_{2}, v_{C Q 1}\left(v_{C Q 2}\right)$ is increased (decreased) because $C_{Q 1}\left(C_{Q 2}\right)$ is charged (discharged) by the resonant current $i_{L r}$. The zero-voltage switching condition of power device $Q_{2}$ is derived as.

$$
i_{\text {Lm2,peak }} \geq \frac{V_{H}}{2} \sqrt{\frac{2 C_{e q}}{L_{m 2}+L_{r}}},
$$

where $C_{e q}=C_{Q 1}=C_{Q 2}$. Based on the switching frequency, magnetizing inductance and turn-ratio, the maximum magnetizing current can be calculated as:

$$
i_{\text {Lm2,peak }}=\frac{\Delta i_{L m 2}}{2} \approx \frac{n V_{L}}{4 L_{m 2} f_{s w}},
$$

From the given dead time, switching frequency, and input and output voltages, the magnetizing inductance $L_{m 2}$ is obtained as:

$$
L_{m 2} \leq \frac{t_{d} n V_{L}}{8 f_{s w} V_{H} C_{e q}}
$$

Mode $4\left[t_{3} \sim t_{4}\right]$ : At $t_{3}, v_{C Q 2}=0$. Since $i_{L r}\left(t_{3}\right)>0$, the antiparallel diode $D_{Q 2}$ is forward biased. Thus, $Q_{2}$ will turn on at zero voltage switching. Due to $i_{Q 4}\left(t_{3}\right)<0, Q_{4}$ turns on to reduce the conduction loss on $Q_{4}$. In this mode, $v_{a b}=-V_{H} / 2, v_{L m 2}=-n V_{L} / 2$, and $i_{L m 2}$ decreases. The current variation on $L_{m 2}$ is $\Delta i_{L m 2,4}=n V_{L} \Delta t_{34} / L_{m 2}$ where $\Delta t_{34}$ is the time duration in mode $4 . L_{r}$ and $C_{r}$ are resonant with $v_{a b}=-V_{H} / 2, v_{L m 2}=-n V_{L}$ and $f_{r}=1 / 2 \pi \sqrt{C_{r} L_{r}}$. If $f_{r}>f_{s w}$, the next step of the circuit operation will go to mode 5. Otherwise, the circuit operation will go to mode 6 .

Mode 5 [ $t_{4} \sim t_{5}$ ]: At time $t_{4}, i_{Q 4}=0$ and synchronous switch $Q_{4}$ turns off. The resonant inductor current $i_{L r}$ will flow through $Q_{2}, C_{r}, L_{r}, L_{m 2}$ and $C_{H 2}$. $L_{r}, C_{r}$ and $L_{m 2}$ are resonant with input voltage $v_{a b}=-V_{H} / 2$.

Mode $6\left[t_{5} \sim T_{s w}+t_{0}\right]$ : At $t_{5}$, power device $Q_{2}$ turns off. Due to $i_{L r}\left(t_{5}\right)<0$, capacitor $C_{Q 1}\left(C_{Q 2}\right)$ is discharged (charged). The soft switching condition of power device $Q_{1}$ is the same as power device $Q_{2}$. The charge (discharge) time of $C_{Q 2}\left(C_{Q 1}\right)$ is sufficiently quick and can be ignored. At time $T_{s w}+t_{0}$, $v_{C Q 1}=0$ and the circuit operations of the developed converter are completed.

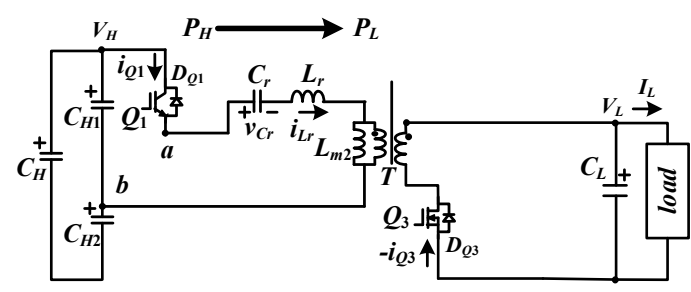

(a)

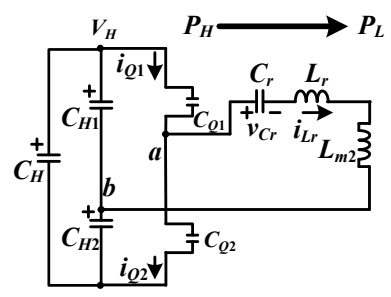

(c)

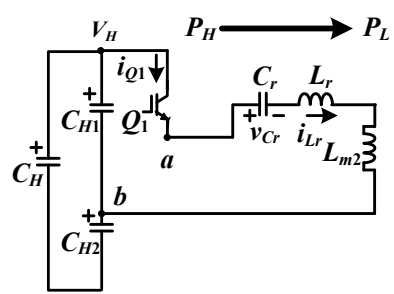

(b)
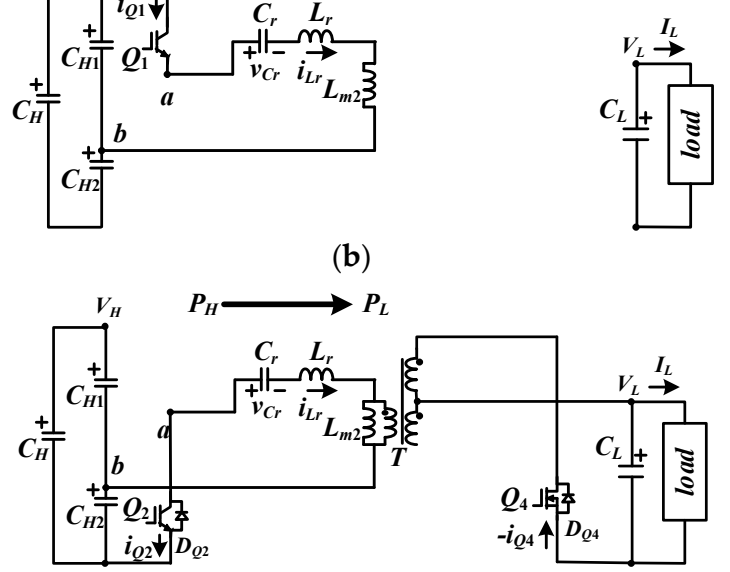

(d)

Figure 4. Cont. 


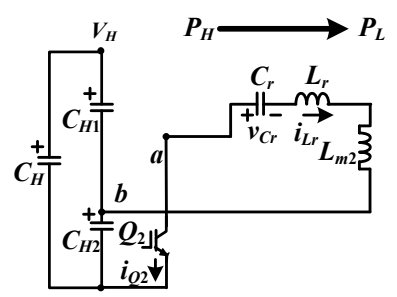

(e)
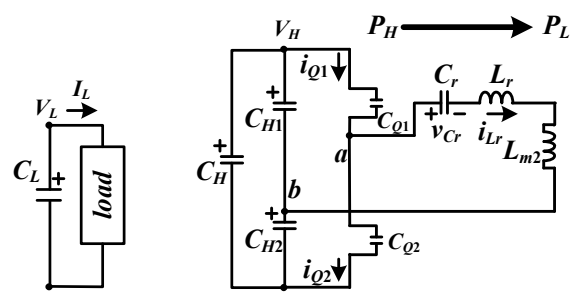

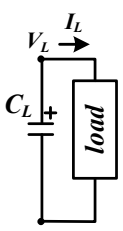

(f)

Figure 4. Equivalent topological circuits for each mode operation under forward power transfer (a) mode 1 (b) mode 2 (c) mode 3 (d) mode 4 (e) mode 5 (f) mode 6.

Although there are several approaches [18-21] to generate square voltage waveforms on the ac side of the converter leg, fundamental frequency analysis [22] is the most useful approach to obtain voltage gain of the proposed circuit under different switching frequency. Based on the switching states of power devices, two square voltage signals are observed on high-voltage side $v_{a b}$ and $v_{L m 2} . C_{r}, L_{\mathrm{r}}$ and $L_{m 2}$ work as a circuit filter to eliminate harmonic signals. Therefore, $v_{a b}$ and $v_{L m 2}$ can be treated as ac voltage's only fundamental frequency to simplify the circuit analysis. The fundamental root mean square $(\mathrm{rms})$ voltages $v_{a b, r m s}$ and $v_{L m 2, r m s}$ are calculated as $\sqrt{2} V_{H} / \pi$ and $2 \sqrt{2} V_{L} n / \pi$. The primary-side fundamental resistance is obtained as $R_{a c 2}=8 n^{2} R_{o, L} / \pi^{2}$ where $R_{o, L}$ is load resistance on the low-voltage side. The equivalent circuit at the fundamental switching frequency under forward power transfer is shown in Figure 3a. Based on a resonant tank consisting of $C_{r}, L_{r}, L_{m 2}$ and $R_{a c 2}$, the voltage gain $G_{H 2 L}(s)$ and $\left|G_{H 2 L}(s)\right|$ under different switching frequency are obtained as:

$$
\begin{gathered}
G_{H 2 L}(s)=\frac{v_{L m 2, r m s}(s)}{v_{a b, r m s}(s)}=\frac{\frac{s L_{m 2} R_{a c 2}}{s L_{m 2}+R_{a c 2}}}{s L_{r}+\frac{1}{s C_{r}}+\frac{s L_{m 2} R_{a c 2}}{s L_{m 2}+R_{a c 2}}}, \\
\left|G_{H 2 L}(F)\right|=\frac{K_{1} F^{2}}{\sqrt{\left[\left(K_{1}+1\right) F^{2}-1\right]^{2}+\left[Q_{1} K_{1} F\left(F^{2}-1\right)\right]^{2}}},
\end{gathered}
$$

where $Q_{1}=\sqrt{L_{r} / C_{r}} / R_{a c 2}, K_{1}=L_{m 2} / L_{r}, F=f_{s w} / f_{r}$ and $f_{r}=1 /\left(2 \pi \sqrt{L_{r} C_{r}}\right)$. Based on (5), the switching frequency is derived with the given high voltage value $V_{H}$, low voltage value $V_{L}$, inductor ratio $K_{1}=L_{m 2} / L_{r}$ and equivalent load resistance $R_{a c 2}$.

\subsection{Reverse Power Flow}

When the proposed converter is worked as backward power transfer to transfer power from $V_{L}$ to $V_{H}$ (Figure $3 \mathrm{~b}$ ), power devices $Q_{3}$ and $Q_{4}$ on the low-voltage side work as active switches to control primary-side voltage $V_{H}$. For having the circuit characteristics of LLC resonant converter, ac switch $S$ is ON so that $L_{m 1}$ is connected between points $a$ and $b$. Based on the amplitude of $\left|i_{L r}\right|$ and $\left|i_{L m 1}\right|$, the anti-parallel diodes $D_{\mathrm{Q} 1}$ and $D_{\mathrm{Q} 2}$ are $\mathrm{ON}$ or OFF and the quasi-square voltage waveform is generated on voltage $v_{a b}$. Likewise, a square waveform is also generated on the primary-side voltage $v_{L m 2}$ based on the ON/OFF state of $Q_{3}$ and $Q_{4}$. Under reverse power transfer operation, $L_{r}, C_{r}$ and $L_{m 1}$ are resonant and the input impedance from the low-voltage side should be an inductive load. Then, $Q_{3}$ and $Q_{4}$ can be operated under zero-voltage condition such that the switching loss is lessened. The key pulse-width modulation signals under backward power transfer operation are demonstrated in Figure 3b. The equivalent topological circuits corresponding to mode operations are demonstrated in Figure 5.

Mode $1\left[t_{0} \sim t_{1}\right.$ ]: The voltage on $C_{Q 3}$ is decreased to zero voltage at time $t_{0}$. Since $i_{Q 3}<0$ and $i_{L r}>0$, the body diode $D_{Q 3}$ of MOSFET $Q_{3}$ conducts so that MOSFET $Q_{3}$ turns on after $t_{0}$ to realize soft switching. In this mode, $i_{L r}\left(t_{0}\right)+i_{L m 1}\left(t_{0}\right)<0, D_{Q 1}$ is conducting, $C_{H 1}$ is charged by $i_{D Q 1}, v_{a b}=V_{C H 1}=V_{H} / 2, v_{L m 2}$ $=n V_{L}, i_{L m 2}$ increases with the slope $n V_{L} / L_{m 2}$ and $i_{L m 1}$ increases with the slope $V_{H} /\left(2 L_{m 1}\right) . L_{r}$ and $C_{r}$ are resonant. Power transfer is from $V_{L}$ to $V_{H}$ in this mode through components $Q_{3}, T, L_{r}, C_{r}$ and $D_{Q 1}$. If $f_{s w}<f_{r}$, the circuit action will go to mode 2 . However, the circuit action will go to mode 3. 


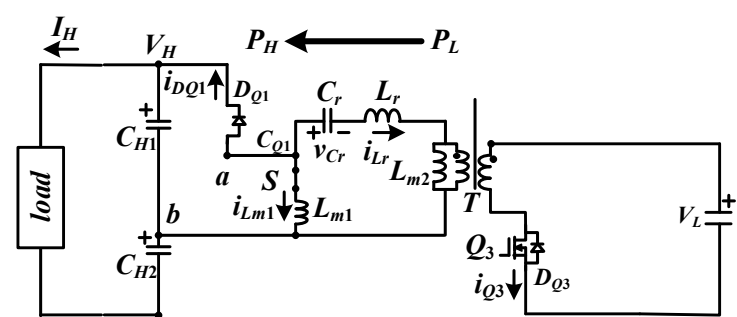

(a)
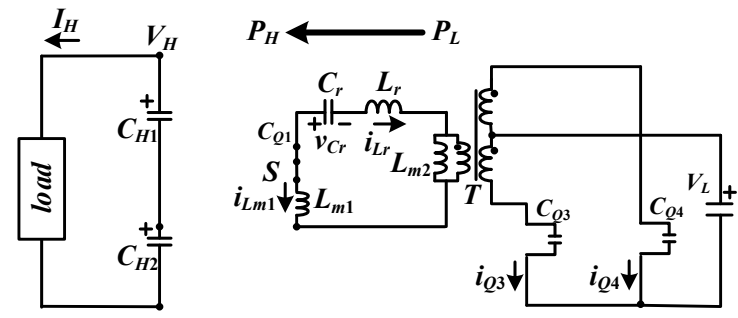

(c)
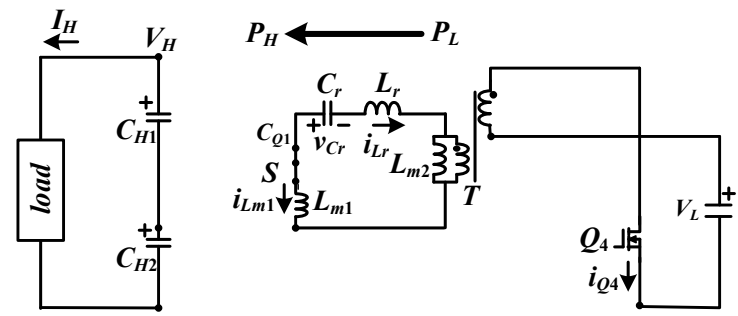

(e)
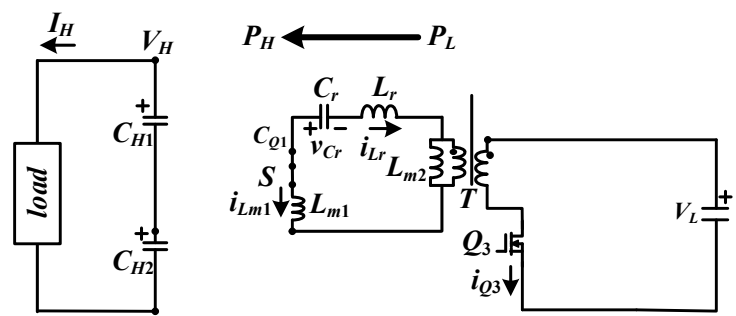

(b)

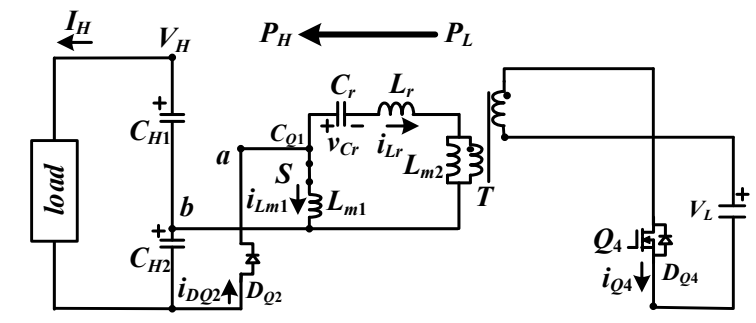

(d)
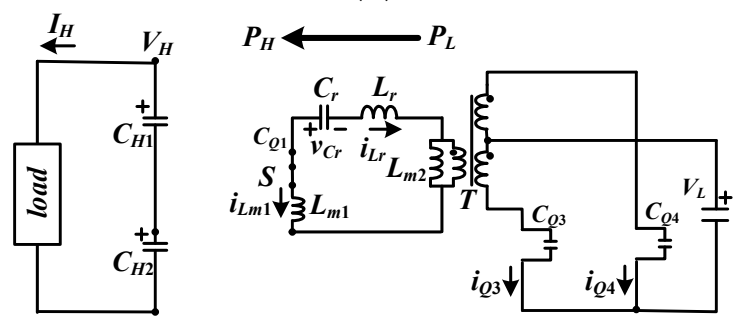

(f)

Figure 5. Equivalent topological circuits at reverse power transfer (a) mode 1 (b) mode 2 (c) mode 3 (d) mode 4 (e) mode 5 (f) mode 6.

Mode $2\left[t_{1} \sim t_{2}\right.$ ]: If $i_{D Q 1}\left(t_{1}\right)=0$, then diode $D_{Q 1}$ is off. The resonant current $i_{L r}$ flows through components $S, C_{r}, L_{r}, T$ and $L_{m 2}$, the components $C_{r}, L_{r}$ and $L_{m 1}$ are resonant with $v_{L m 2}=n V_{L}$, and the resonant frequency is $f_{p}=1 / 2 \pi \sqrt{C_{r}\left(L_{r}+L_{m 1}\right)}<<f_{r}$.

Mode $3\left[t_{2} \sim t_{3}\right.$ ]: At $t_{2}$, power device $Q_{3}$ turns off. Since $i_{Q 3}>0$ and $i_{Q 4}<0, C_{Q 3}$ is charged and $C_{Q_{4}}$ is discharged. The zero-voltage switching condition of $Q_{4}$ is obtained as:

$$
\left(L_{m 1}+L_{r}\right) i_{\text {Lm1,peak }}^{2}+L_{m 2} i_{\text {Lm2,peak }}^{2} \geq 2 C_{Q, s} V_{L^{\prime}}^{2}
$$

where $C_{Q, s}=C_{Q 3}=C_{Q 4}, i_{L m 2, \text { peak }} \approx n V_{L} /\left(4 L_{m 2} f_{s w}\right)$ and $i_{L m 1, p e a k} \approx V_{H} /\left(8 L_{m 1} f_{s w}\right)$. The time duration in this mode is calculated when $v_{C Q 4}$ is decreased to zero voltage.

$$
\Delta t_{23} \approx \frac{2 V_{L} C_{Q, s}}{n\left[i_{L m 1, p e a k}+i_{L m 2, p e a k}\right]}=\frac{16 L_{m 1} L_{m 2} f_{s w} V_{L} C_{Q, s}}{n\left(L_{m 2} V_{H}+2 n L_{m 1} V_{L}\right)} \leq t_{d}
$$

where $t_{d}$ is a dead time.

Mode $4\left[t_{3} \sim t_{4}\right]$ : At time $t_{3}, v_{C Q 4}=0$. Then, $D_{Q 4}$ becomes forward biased. Since $i_{Q 4}\left(t_{3}\right)$ is negative, $Q_{4}$ can be turned on at this instant without turn-on switching loss. In this mode, $D_{Q_{2}}$ is forward biased, $Q_{4}$ is turned on, $v_{a b}=v_{L m 1}=-V_{H} / 2, v_{L m 2}=-n V_{L}$, and $C_{r}$ and $L_{r}$ are resonant. If $f_{s w}<f_{r}$, the next operating mode will go to mode 5 . Otherwise, the next operating mode is mode 6.

Mode $5\left[t_{4} \sim t_{5}\right.$ ]: If $f_{s w}<f_{r}, i_{D Q 2}=0$ before active device $Q_{4}$ turns off. At time $t_{4}, i_{D Q 2}=0$ and $D_{Q 2}$ is reverse biased. Therefore, the resonant inductor current $i_{L r}$ flows through $L_{m 1}, C_{r}, L_{r}$ and T. $L_{m 1}, C_{r}$ and $L_{r}$ are resonant under $v_{L m 2}=-n V_{L}$. 
Mode $6\left[t_{5} \sim T_{s w}+t_{0}\right]: Q_{4}$ is turned off at $t_{5}$. Then, $C_{Q 3}$ and $C_{Q 4}$ are discharged and charged, respectively. At time $T_{s w}+t_{0}, v_{\mathrm{CQ} 3}=0$. Then the circuit operation will go to mode 1 for next switching period.

The operation of the proposed converter at reverse power transfer is like the forward power transfer. $Q_{3}$ and $Q_{4}$ are controlled by frequency-mode operation. The resonant tank included $L_{r}, C_{\mathrm{r}}$ and $L_{m 1}$ and is operated as a band-pass filter to eliminate harmonics. In Figure $3 \mathbf{b}$, the input fundamental $r m s$ voltage $v_{L m 2, r m s}=2 \sqrt{2} n V_{L} / \pi$. The resonant tank includes $R_{a c 1}, L_{m 1}, C_{r}$ and $L_{r}$. The equivalent resistance $R_{a c 1}=2 R_{o, H} / \pi^{2}$. The voltage gains $G_{L 2 H}(s)$ and $\left|G_{L 2 H}(s)\right|$ under reverse power transfer are calculated as:

$$
\begin{gathered}
G_{L 2 H}(s)=\frac{v_{L m 1, r m s}(s)}{v_{L m 2, r m s}(s)}=\frac{\frac{s L_{m 1} R_{a c 1}}{s L_{m 1}+R_{a c 1}}}{\frac{1}{s C_{r}}+s L_{r}+\frac{s L_{m 1} R_{a c 1}}{s L_{m 1}+R_{a c 1}}}, \\
\left|G_{L 2 H}(F)\right|=\frac{K_{2} F^{2}}{\sqrt{\left[\left(K_{2}+1\right) F^{2}-1\right]^{2}+\left[Q_{2} K_{2} F\left(F^{2}-1\right)\right]^{2}}},
\end{gathered}
$$

where $f_{r}=1 /\left(2 \pi \sqrt{L_{r} C_{r}}\right), Q_{2}=\sqrt{L_{r} / C_{r}} / R_{a c 1}, K_{2}=L_{m 1} / L_{r}$ and $F=f_{s w} / f_{r}$. Based on Equation (9), the necessary switching frequency $f_{s w}$ is calculated from the given parameters $V_{H}, V_{L}, K_{2}=L_{m 1} / L_{r}$ and $R_{a c 1}$.

\section{Experimental Waveforms}

In this section, a design procedure of the studied circuit is discussed and the experiments are demonstrated. For forward power operation, the high-side voltage $V_{H}=350 \mathrm{~V} \sim 400 \mathrm{~V}$ and the low-side voltage $V_{L}=48 \mathrm{~V}$. For reverse power transfer, the low-voltage $V_{L}$ varies from $38 \mathrm{~V}$ to $52 \mathrm{~V}$ and $V_{H}=400 \mathrm{~V}$. The power rating $P_{o, \text { rated }}=480 \mathrm{~W}$. Based on Equations (5) and (9), the voltage transfer functions for both forward power operation and reverse power operation are alike. To simplify the circuit design, only the forward power transfer is discussed. The voltage gain $\left|G_{H 2 L}(\mathrm{~s})\right|$ under $V_{H}=400 \mathrm{~V}$ is set to one. Then, the turn-ratio $n$ of power transformer $T$ is calculated as $n=\left|G_{H 2 L}\right| \times \frac{V_{H, \max }}{2 V_{L, \max }}=1 \times \frac{400}{2 \times 52} \approx 3.85$. In this prototype, the selected primary turns and secondary turns are 23 and 6 , respectively. According to turn-ratio $n$, the dc gains are derived under $48 \mathrm{~V}$ output voltage.

$$
\begin{aligned}
& \left|G_{H 2 L}\right|_{d c, \min }=\frac{2 n V_{L, n o m}}{V_{H, \max }}=\frac{2 \times(23 / 6) \times 48}{400} \approx 0.92, \\
& \left|G_{H 2 L}\right|_{d c, \text { max }}=\frac{2 n V_{L, n o m}}{V_{H, \text { min }}}=\frac{2 \times(23 / 6) \times 48}{350} \approx 1.05,
\end{aligned}
$$

Since the maximum gain of $\left|G_{H 2 L}(\mathrm{~s})\right|$ is 1.05 , the select inductor ratio $K_{1}$ and quality factor $Q_{1}$ should be selected under the full load and minimum input voltage case. The larger $K_{1}$ can reduce circulating current loss and the smaller $K_{1}$ can increase voltage gain. Since the maximum voltage gain of $\left|G_{H 2 L}(\mathrm{~s})\right|$ is $1.05, K_{1}=13$ is selected in the prototype to lessen the circulating current loss. The maximum gain of $\left|G_{H 2 L}(\mathrm{~s})\right|$ under $K_{1}=13$ and $Q_{1}=0.35$ is close to 1.18 . Since $n=23 / 6, R_{a c 2}$ at rated power can be obtained as:

$$
R_{a c 2}=\frac{8 n^{2}}{\pi^{2}} R_{o, L}=\frac{8 \times(23 / 6)^{2}}{3.14159^{2}} \times \frac{48}{10} \approx 57.17 \Omega,
$$

Since $f_{r}$ is selected as $100 \mathrm{kHz}, C_{r}$ and $L_{r}$ are calculated as $C_{r}=1 / 2 \pi Q_{1} f_{r} R_{a c 2} \approx 79.5 \mathrm{nF}$ and $L_{r}=1 /\left(2 \pi f_{r}\right)^{2} C_{r} \approx 31.86 \mu \mathrm{H}$. The selected components are $C_{r}=78 \mathrm{nF}, L_{r}=32 \mu \mathrm{H}$ and $\mathrm{L}_{\mathrm{m} 2}=\mathrm{K}_{1} \mathrm{~L}_{\mathrm{r}}=13 \times 32=416 \mu \mathrm{H}$. The secondary-side $r m s$ current reflected to the primary-side is obtained as $I_{r m s, p}=\frac{\pi I_{o}}{2 \sqrt{2} n} \approx 2.9 \mathrm{~A}$. The minimum switching frequency of the prototype circuit is obtained as $f_{s w \text {,min }}=1 / 2 \pi \sqrt{C_{r}\left(L_{r}+L_{m 2}\right)} \approx 27 \mathrm{kHz}$. The maximum $r m s$ magnetizing current occurs at minimum switching frequency $f_{s w, m i n}$ and can be expressed as $I_{L m 2, r m s}=\frac{1}{2 \sqrt{3}} \frac{n V_{L}}{4 f_{s w, m i n} L_{m 2}} \approx 1.18 \mathrm{~A}$. The $r m s$ current of $L_{r}$ is obtained as $I_{L r, r m s}=\sqrt{I_{L m 2, r m s}^{2}+I_{r m s, p}^{2}} \approx 3.13$ A. The maximum peak 
voltage on capacitor $C_{r}$ is derived as $v_{C r, p e a k}=\frac{\sqrt{2} I_{L r, r m s}}{2 \pi f_{s w, m i n} C_{r}} \approx 334.5 \mathrm{~V}$. The theoretical voltage ratings of $Q_{1} \sim Q_{4}$ are $v_{Q 1, \text { stress }}=v_{Q 2, \text { stress }}=400 \mathrm{~V}$ and $v_{Q 3, \text { stress }}=v_{Q 4, \text { stress }}=104 \mathrm{~V}$. The rms switch currents are $I_{Q 1, r m s}=I_{\mathrm{Q} 2, r m s}=I_{L r, r m s} / \sqrt{2} \approx 2.21 \mathrm{~A}$ and $I_{Q 3, r m s}=I_{Q 4, r m s}=n I_{\mathrm{sec}, p} / \sqrt{2} \approx 7.85 \mathrm{~A}$. Power devices $Q_{1}$ and $Q_{2}$ are implemented using IRG4PC40W with $600 \mathrm{~V} / 20 \mathrm{~A}$ rating, and power devices $Q_{3}$ and $Q_{4}$ are implemented using IRFB4321PbF with $150 \mathrm{~V} / 85 \mathrm{~A}$ rating. Two SiHG20N50C with $500 \mathrm{~V} / 20 \mathrm{~A}$ rating with back-to-back connection is adopted to implement ac switch $S$. The selected inductor $L_{m 1}=224 \mu \mathrm{H}$ means the inductor ratio $K_{2}=L_{m 1} / L_{r}=7$ at reverse power transfer condition. In the prototype circuit, the input and output capacitances are $C_{H 1}=C_{H 2}=180 \mu \mathrm{F} / 400 \mathrm{~V}$ and $C_{L}=2200 \mu \mathrm{F} / 100 \mathrm{~V}$.

Based on the circuit values calculated in design procedure, a prototype circuit was implemented, and the experiments are provided to verify the effectiveness of the developed circuit. Figure 6 gives the photograph of the proposed prototype. The test results of the developed converter operated at forward power transfer are shown in Figures 7-10. Likewise, Figures 11-14 show the test results under backward power transfer. Figure 7 gives the test results of the developed circuit under $100 \%$ load and $V_{H}=350 \mathrm{~V}$ case. Since $f_{s w}$ is less than $f_{r}$, the secondary-side currents are decreased to zero before active device is turned off. Similarly, Figure 8 illustrates the experimental results under $100 \%$ rated power and $V_{H}=400 \mathrm{~V}$ case. It is clear that $f_{s w}$ (switching frequency) is close to $f_{r}$ (resonant frequency) so that $i_{L r}$ and $v_{C r}$ are close to sinusoidal waveforms. Figures 9 and 10 demonstrate the test waveforms of the power devices $Q_{1}$ and $Q_{2}$ under different input voltage and load situations. It is observed that zero-voltage turn-on switching of $Q_{1}$ and $Q_{2}$ are achieved from 20 to $100 \%$ of rated power. The switching frequency at $V_{H}=350 \mathrm{~V}$ case is less than the switching frequency at $V_{H}=400 \mathrm{~V}$ case. For forward power transfer, the circuit efficiencies are $94.73 \%(90 \%), 94.8 \%$ (93.2\%) and 93.9\% $(92.3 \%)$ at $20 \%, 50 \%$ and $100 \%$ rated power, respectively, under $400 \mathrm{~V}(350 \mathrm{~V})$ input. The measured switching frequencies are $151.3 \mathrm{kHz}(67.4 \mathrm{kHz}), 114.3 \mathrm{kHz}(60 \mathrm{kHz})$ and $97.6 \mathrm{kHz}(52.85 \mathrm{kHz})$ at $20 \%, 50 \%$ and $100 \%$ rated power, respectively, under $400 \mathrm{~V}(350 \mathrm{~V})$ input. Figures 11 and 12 give the test results of main voltage and current waveforms under backward power transfer at input voltage $V_{L}=38 \mathrm{~V}$ and $52 \mathrm{~V}$ cases. Based on test results, the switching frequencies $f_{s w}$ under these cases are all less than $f_{r}$ (resonant frequency). Therefore, the reverse recovery current loss on $D_{Q 1}$ and $D_{Q 2}$ is improved. Figures 13 and 14 demonstrate the measured waveforms of power devices $Q_{3}$ and $Q_{4}$ at different load and voltage cases. The soft switching characteristics of $Q_{3}$ and $Q_{4}$ are realized from $20 \%$ of rated power. Based on test results shown in Figures 7-14, the experimental waveforms are agreed with the theoretical waveforms in the system analysis. For backward power transfer, the circuit efficiencies are $88.2 \%(87.1 \%), 91.1 \%(90.4 \%)$ and $90.2 \%(90.1 \%)$ at $20 \%, 50 \%$ and $100 \%$ rated power, respectively, under $52 \mathrm{~V}(38 \mathrm{~V})$ input. The measured switching frequencies are $72.5 \mathrm{kHz}(62.8 \mathrm{kHz})$, $60.2 \mathrm{kHz}(53.4 \mathrm{kHz})$ and $53.5 \mathrm{kHz}(48.8 \mathrm{kHz})$ at $20 \%, 50 \%$ and $100 \%$ rated power, respectively, under $52 \mathrm{~V}$ $(38 \mathrm{~V})$ input. Because of low voltage and high current input at the low voltage side under backward power transfer, more conduction loss will be introduced on power switches at the low voltage side. Thus, the circuit efficiency under backward power operation is less than the circuit efficiency under forward power operation. 


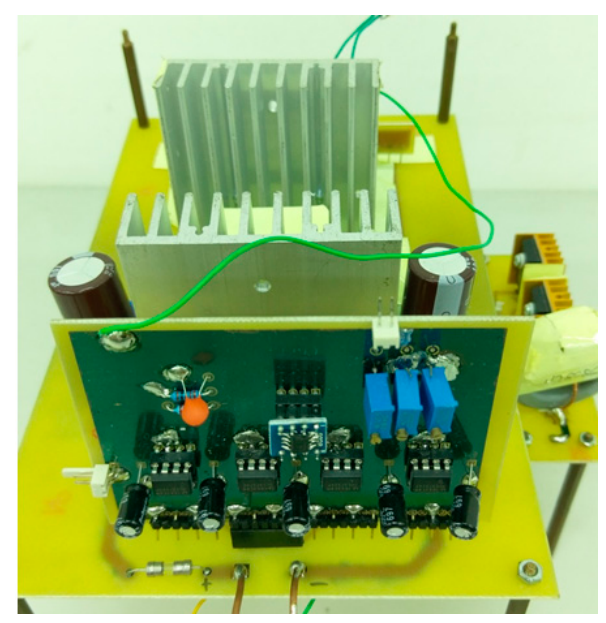

Figure 6. Photograph of the proposed prototype.

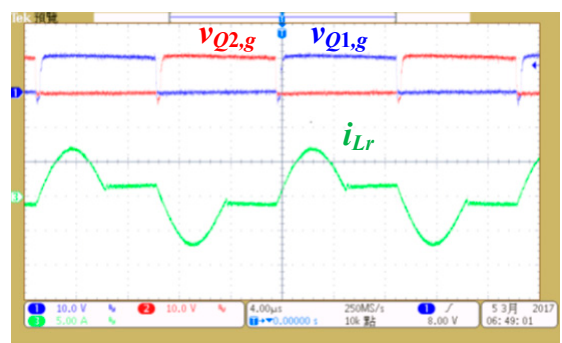

(a)

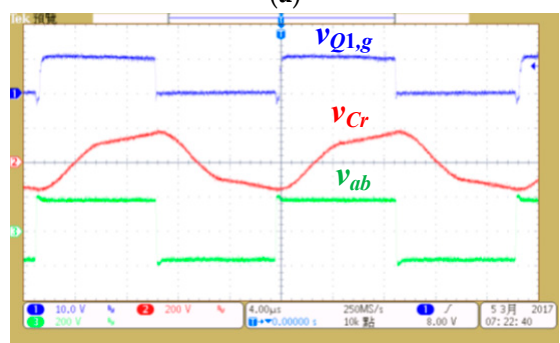

(b)

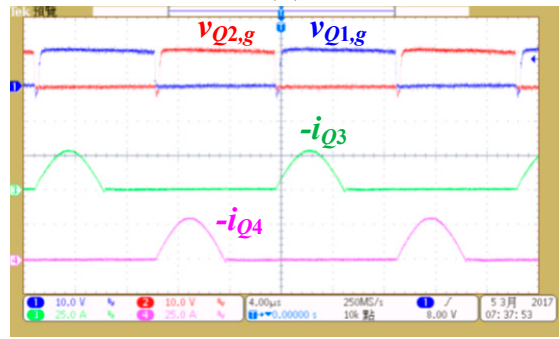

(c)

Figure 7. Test results under forward power transfer and full load with $V_{H}=350 \mathrm{~V}$ (a) $v_{Q 1, g}, v_{Q 2, g}$ and $i_{L r}\left[v_{Q 1, g}, v_{Q 2, g}: 10 \mathrm{~V} /\right.$ div; $i_{L r}: 5 \mathrm{~A} /$ div; time: $\left.4 \mu \mathrm{s} / \operatorname{div}\right](\mathbf{b}) v_{Q 1, g}, v_{C r}$ and $v_{a b}\left[v_{Q 1, g}: 10 \mathrm{~V} /\right.$ div; $v_{C r}, v_{a b}$ : $200 \mathrm{~V} /$ div; time: $4 \mu \mathrm{s} / \operatorname{div}](\mathbf{c}) v_{Q 1, g}, v_{Q 2, g},-i_{Q 3}$ and $-i_{Q 4}\left[v_{Q 1, g}, v_{Q 2, g}: 10 \mathrm{~V} /\right.$ div; $-i_{Q 3},-i_{Q 4, g}: 25 \mathrm{~A} /$ div; time: $4 \mu \mathrm{s} / \mathrm{div}]$. 


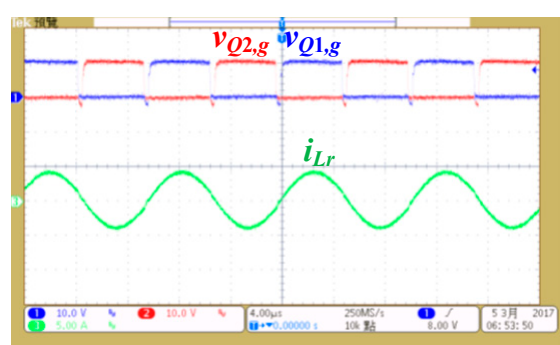

(a)

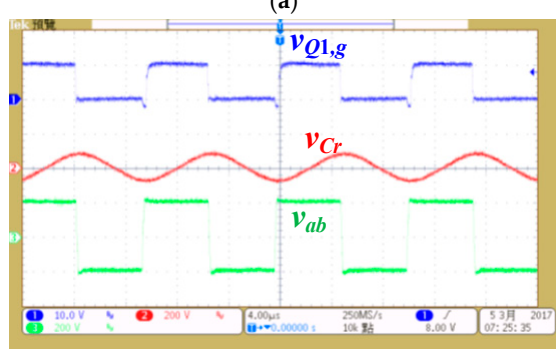

(b)

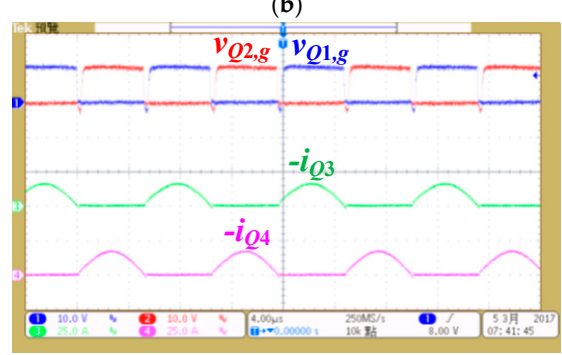

(c)

Figure 8. Test results under forward power transfer and full load with $V_{H}=400 \mathrm{~V}(\mathbf{a}) v_{\mathrm{Q} 1, g}, v_{\mathrm{Q} 2, g}$ and $i_{\mathrm{Lr}}\left[v_{\mathrm{Q} 1, g}\right.$, $v_{Q 2, g}: 10 \mathrm{~V} /$ div; $i_{L r}: 5 \mathrm{~A} /$ div; time: $\left.4 \mu \mathrm{s} / \operatorname{div}\right](\mathbf{b}) v_{Q 1, g}, v_{C r}$ and $v_{a b}\left[v_{Q 1, g}: 10 \mathrm{~V} /\right.$ div; $v_{C r}, v_{a b}: 200 \mathrm{~V} /$ div; time: $4 \mu \mathrm{s} / \mathrm{div}]$ (c) $v_{\mathrm{Q} 1, g}, v_{\mathrm{Q} 2, g},-i_{\mathrm{Q} 3}$ and $-i_{\mathrm{Q} 4}\left[v_{\mathrm{Q} 1, g}, v_{\mathrm{Q} 2, g}: 10 \mathrm{~V} / \mathrm{div} ;-i_{\mathrm{Q} 3},-i_{\mathrm{Q} 4, g}: 25 \mathrm{~A} / \mathrm{div} ;\right.$ time: $\left.4 \mu \mathrm{s} / \mathrm{div}\right]$.

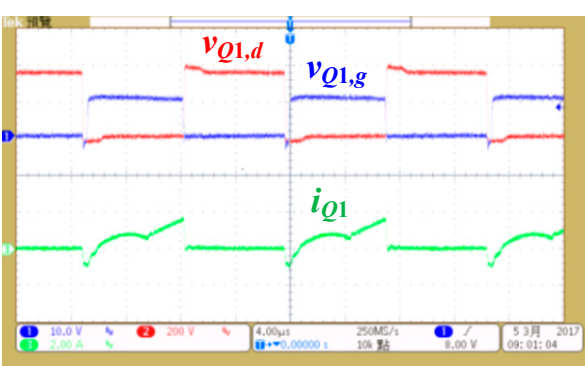

(a)

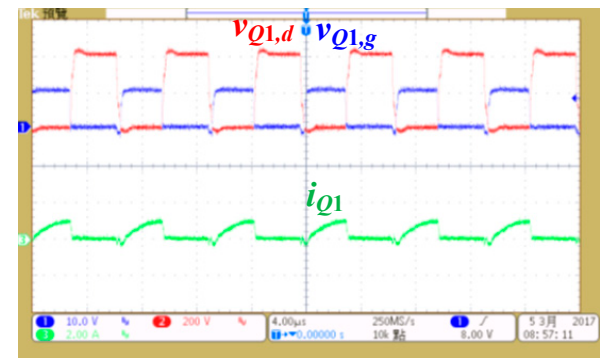

(c)

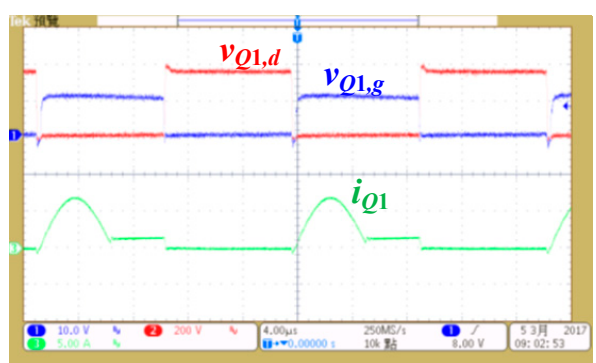

(b)

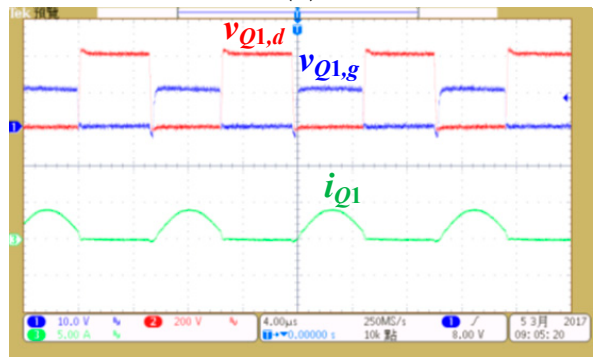

(d)

Figure 9. Test results of $Q_{1}$ under (a) $V_{H}=350 \mathrm{~V}$ and $20 \%$ load $\left[v_{Q 1, g}: 10 \mathrm{~V} /\right.$ div; $v_{Q 1, d}: 200 \mathrm{~V} /$ div; $i_{Q 1}: 2$ A/div; time: $4 \mu \mathrm{s} / \operatorname{div}]$ (b) $V_{H}=350 \mathrm{~V}$ and $100 \%$ load $\left[v_{\mathrm{Q} 1, g}: 10 \mathrm{~V} / \mathrm{div} ; v_{\mathrm{Q} 1, d}: 200 \mathrm{~V} / \mathrm{div} ; i_{\mathrm{Q} 1}: 5 \mathrm{~A} / \mathrm{div}\right.$; time: $4 \mu \mathrm{s} / \operatorname{div}$ ] (c) $V_{H}=400 \mathrm{~V}$ and $20 \%$ load [ $v_{Q 1, g}: 10 \mathrm{~V} /$ div; $v_{Q 1, d}: 200 \mathrm{~V} /$ div; $i_{Q 1}: 2 \mathrm{~A} /$ div; time: $\left.4 \mu \mathrm{s} / \mathrm{div}\right]$ (d) $V_{H}=400 \mathrm{~V}$ and $100 \%$ load $\left[v_{Q 1, g}: 10 \mathrm{~V} /\right.$ div; $v_{Q 1, d}: 200 \mathrm{~V} /$ div; $i_{Q 1}: 5 \mathrm{~A} /$ div; time: $4 \mu \mathrm{s} /$ div]. 


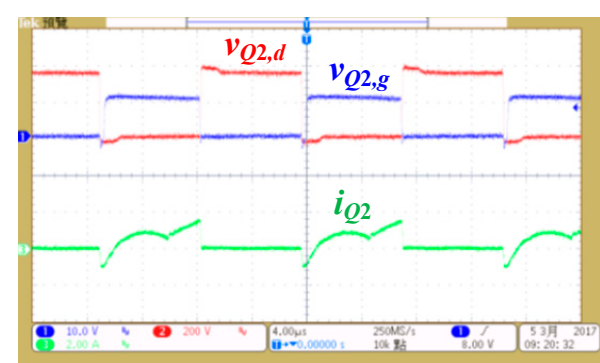

(a)

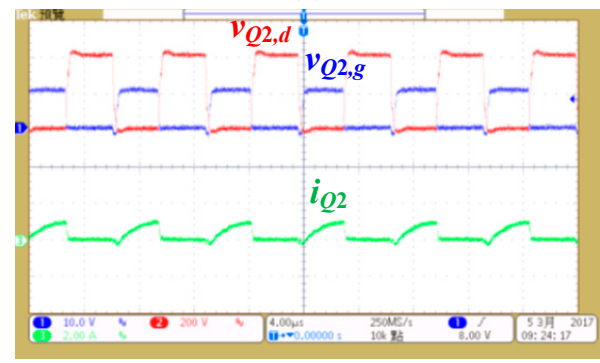

(c)

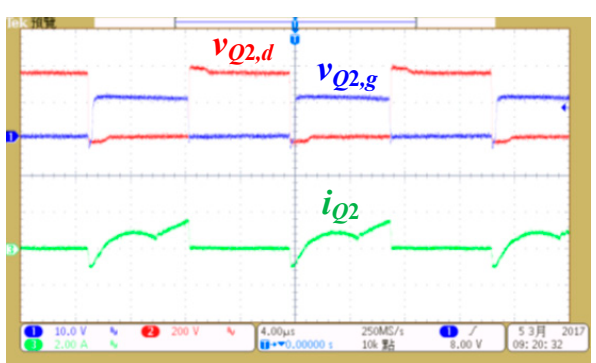

(b)

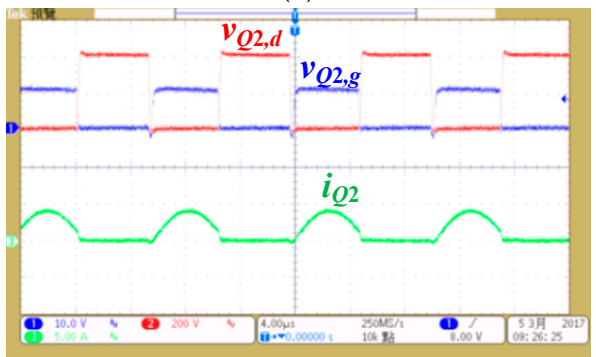

(d)

Figure 10. Test results of $Q_{2}$ under (a) $V_{H}=350 \mathrm{~V}$ and $20 \%$ load $\left[v_{\mathrm{Q} 2, g}: 10 \mathrm{~V} /\right.$ div; $v_{\mathrm{Q} 2, d}: 200 \mathrm{~V} /$ div; $i_{\mathrm{Q} 2}$ : $2 \mathrm{~A} /$ div; time: $4 \mu \mathrm{s} / \operatorname{div}]$ (b) $V_{H}=350 \mathrm{~V}$ and $100 \%$ load $\left[v_{\mathrm{Q} 2, g}: 10 \mathrm{~V} / \mathrm{div} ; v_{\mathrm{Q} 2, d}: 200 \mathrm{~V} / \mathrm{div} ; i_{\mathrm{Q} 2}: 5 \mathrm{~A} /\right.$ div; time: $4 \mu \mathrm{s} / \mathrm{div}$ ] (c) $V_{H}=400 \mathrm{~V}$ and $20 \%$ load [ $v_{Q 2, g}: 10 \mathrm{~V} / \mathrm{div} ; v_{Q 2, d}: 200 \mathrm{~V} / \mathrm{div} ; i_{Q 2}: 2 \mathrm{~A} / \mathrm{div} ;$ time: $\left.4 \mu \mathrm{s} / \mathrm{div}\right]$ (d) $V_{H}=400 \mathrm{~V}$ and $100 \%$ load $\left[v_{Q 2, g}: 10 \mathrm{~V} /\right.$ div; $v_{Q 2, d}: 200 \mathrm{~V} /$ div; $i_{Q 2}: 5 \mathrm{~A} /$ div; time: $4 \mu \mathrm{s} /$ div].

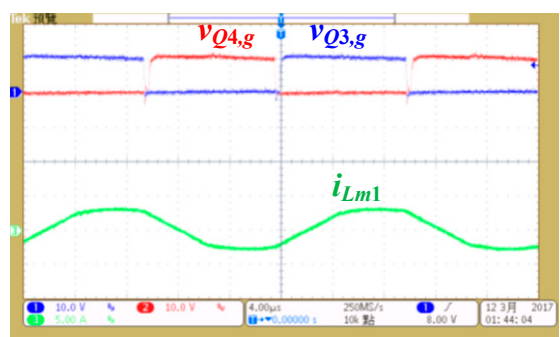

(a)

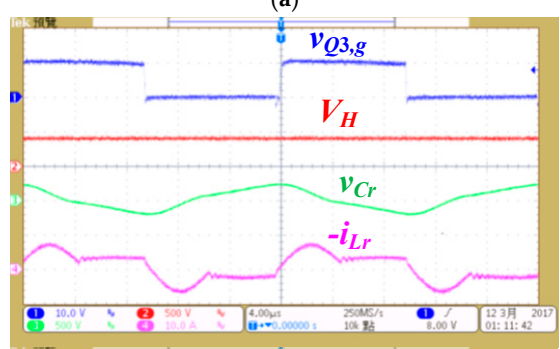

(b)

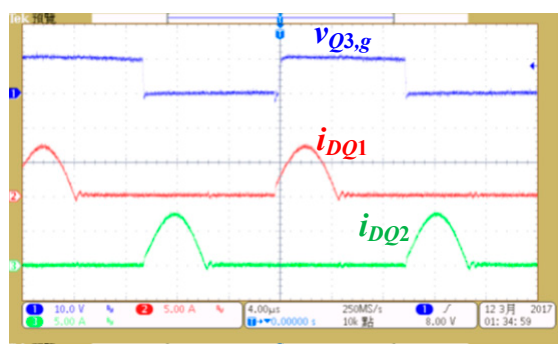

(c)

Figure 11. Test results under backward power transfer and full load with $V_{L}=38 \mathrm{~V}$ (a) $v_{Q 3, g}, v_{Q 4, g}$ and $i_{L m 1}\left[v_{Q 3, g}, v_{Q 4, g}: 10 \mathrm{~V} /\right.$ div; $i_{L m 1}: 5 \mathrm{~A} /$ div; time: $\left.4 \mu \mathrm{s} / \operatorname{div}\right](\mathbf{b}) v_{\mathrm{Q}, g}, V_{H}, v_{C r}$ and $-i_{L r}\left[v_{Q 3, g}: 10\right.$ $\mathrm{V} / \operatorname{div} ; V_{H}, v_{C r}: 500 \mathrm{~V} / \operatorname{div} ;-i_{L r}: 10 \mathrm{~A} / \operatorname{div} ;$ time: $\left.4 \mu \mathrm{s} / \operatorname{div}\right]$ (c) $v_{Q 3, g}, i_{D Q 1}$ and $i_{D Q 2}\left[v_{Q 3, g}: 10 \mathrm{~V} /\right.$ div; $i_{D Q 1}, i_{D Q 2}: 5 \mathrm{~A} /$ div; time: $4 \mu \mathrm{s} /$ div]. 


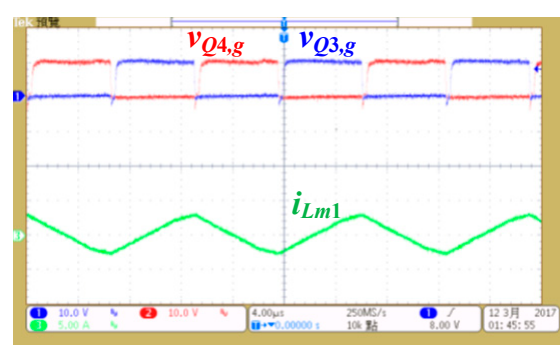

(a)

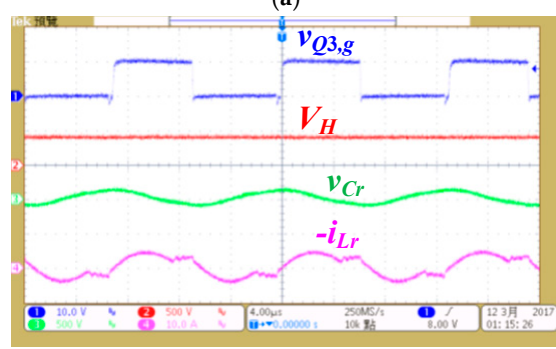

(b)

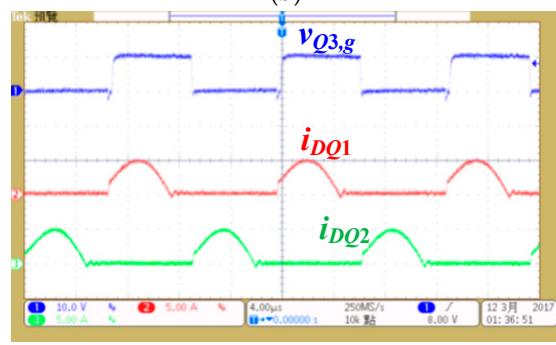

(c)

Figure 12. Test results under backward power transfer and full load with $V_{L}=52 \mathrm{~V}(\mathbf{a}) v_{Q 3, g}, v_{Q 4, g}$ and $i_{L m 1}\left[v_{Q 3, g}, v_{Q 4, g}: 10 \mathrm{~V} /\right.$ div; $i_{L m 1}: 5 \mathrm{~A} /$ div; time: $4 \mu \mathrm{s} /$ div $](\mathbf{b}) v_{\mathrm{Q} 3, g}, V_{H}, v_{C r}$ and $-i_{L r}\left[v_{Q 3, g}: 10 \mathrm{~V} /\right.$ div; $V_{H}, v_{C r}: 500 \mathrm{~V} / \mathrm{div} ;-i_{L r}: 10 \mathrm{~A} / \mathrm{div} ;$ time: $\left.4 \mu \mathrm{s} / \mathrm{div}\right](\mathrm{c}) v_{\mathrm{Q} 3, g}, i_{D Q 1}$ and $i_{D Q 2}\left[v_{Q 3, g}: 10 \mathrm{~V} / \mathrm{div} ; i_{D Q 1}\right.$, $i_{D Q 2}: 5 \mathrm{~A} / \mathrm{div}$; time: $\left.4 \mu \mathrm{s} / \operatorname{div}\right]$.

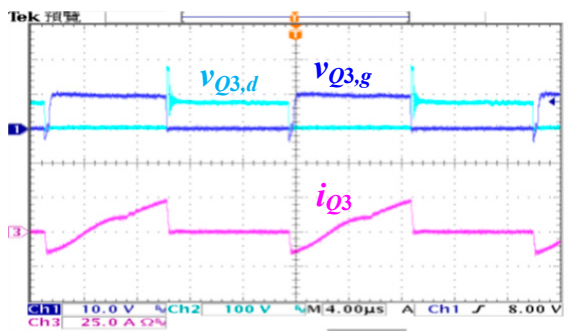

(a)

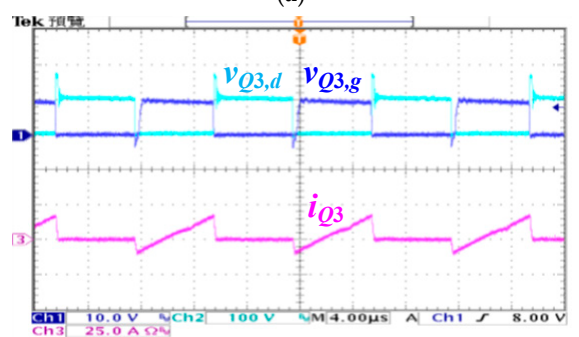

(c)

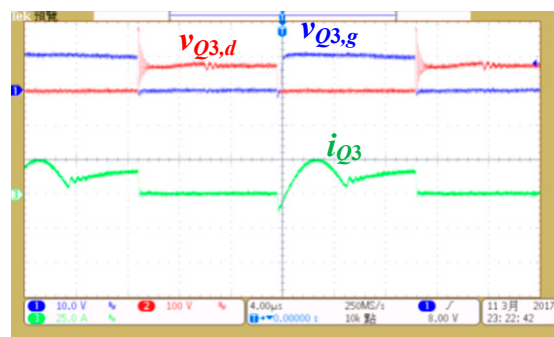

(b)

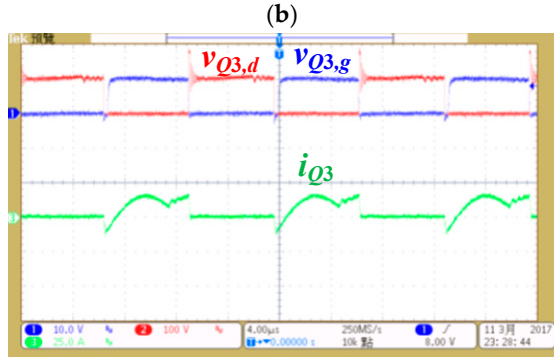

(d)

Figure 13. Test results of the power device $\mathrm{Q}_{3}$ under backward power transfer (a) $V_{L}=38 \mathrm{~V}$ and $20 \%$ load (b) $V_{L}=380 \mathrm{~V}$ and $100 \%$ load (c) $V_{L}=52 \mathrm{~V}$ and $20 \%$ load (d) $V_{L}=52 \mathrm{~V}$ and $100 \%$ load $\left[v_{Q 3,8}\right.$ : $10 \mathrm{~V} /$ div; $v_{Q 3, d}: 100 \mathrm{~V} ; i_{\mathrm{Q} 3}: 25 \mathrm{~A} /$ div; time: $4 \mu \mathrm{s} /$ div]. 


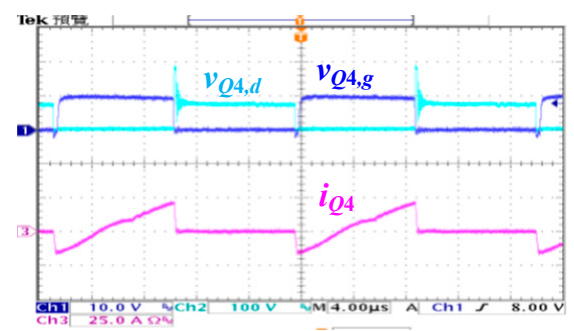

(a)

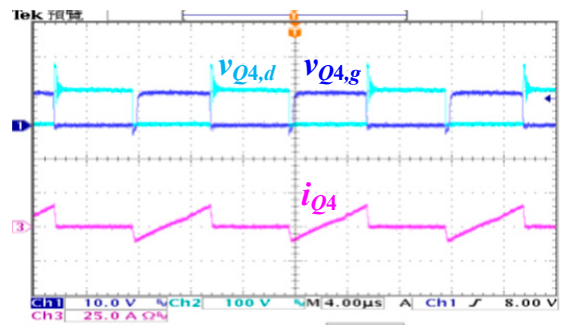

(c)

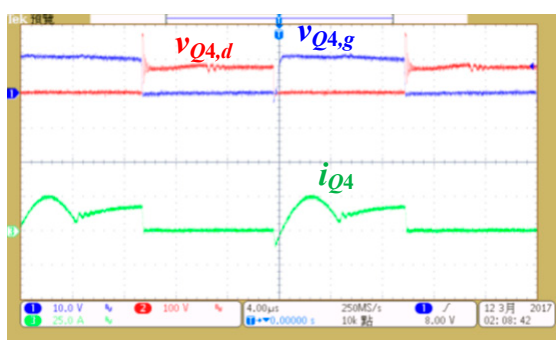

(b)

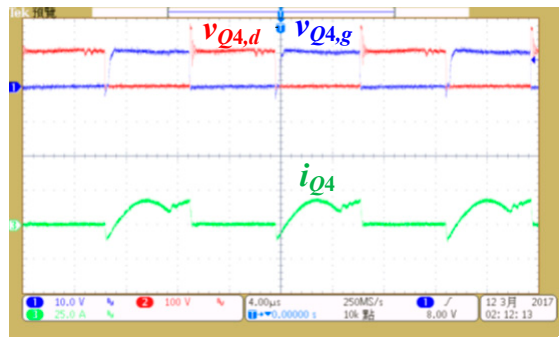

(d)

Figure 14. Test results of the power device $\mathrm{Q}_{4}$ under backward power transfer (a) $V_{L}=38 \mathrm{~V}$ and $20 \%$ load (b) $V_{L}=38 \mathrm{~V}$ and $100 \%$ load (c) $V_{L}=52 \mathrm{~V}$ and $20 \%$ load (d) $V_{L}=52 \mathrm{~V}$ and $100 \%$ load $\left[v_{Q 4, g}\right.$ : $10 \mathrm{~V} /$ div; $v_{Q 4, d}: 100 \mathrm{~V} ; i_{Q 4}: 25 \mathrm{~A} /$ div; time: $4 \mu \mathrm{s} /$ div].

\section{Conclusions}

A bidirectional resonant converter is studied and implemented to achieve bidirectional power transfer capability. To achieve the dual symmetric resonant behavior for both forward power operation and backward power operation and reduce the circulating current loss under forward power transfer, an ac switch and a parallel inductor is used on the high voltage side. The input impedance of the proposed circuit is regulated with the frequency-modulation scheme. The soft switching of active devices is realized. The forward and backward power transfers have the same LLC circuit characteristics. The parallel inductor on the primary-side is disconnected under forward power transfer in order to improve the circulating current loss. Finally, experimental waveforms are provided to demonstrate the achievability of the developed converter. The main drawback of the proposed converter is more conduction loss on magnetizing inductor during the backward power transfer, because the low-side voltage will introduce a magnetizing current, and this is an additional power loss on low-side power devices and transformers. Therefore, the circuit efficiency at the backward power transfer is less than forward power transfer. In order to overcome low circuit efficiency at backward power flow in the proposed converter, the symmetric resonant circuit, such as CLLLC or CLLC, instead of using half-bridge or full-bridge circuit topology, may be researched and studied in future work.

Author Contributions: B.-R.L. designed the main parts of the project and was also responsible for writing the paper. Y.-C.H. built the prototype circuit and measured experimental waveforms.

Acknowledgments: This study is supported by the Ministry of Science and Technology, Taiwan, under contract MOST 107-2221-E-224-013.

Conflicts of Interest: The author declares no potential conflict of interest.

\section{References}

1. Zhao, J.F.; Jiang, J.G.; Yang, X.W. AC-DC-DC isolated converter with bidirectional power flow capability. IET Power Electron. 2010, 3, 472-479. [CrossRef]

2. Singh, A.K.; Pathak, M.K. Single-phase bidirectional ac/dc converter for plug-in electric vehicles with reduced conduction losses. IET Power Electron. 2018, 11, 140-148. [CrossRef]

3. Prasanna, U.R.; Singh, A.K.; Rajashekara, K. Novel bidirectional single-phase single-stage isolated ac-dc converter with PFC for charging of electric vehicles. IEEE Trans. Transport. Electrif. 2017, 3, 536-544. [CrossRef] 
4. Gu, L.; Jin, K. A three-phase bidirectional ac/dc converter with Y- $\triangle$ controlled transformers. IEEE Trans. Power Electron. 2016, 31, 8115-8125.

5. Yilmaz, M.; Krein, P.T. Review of battery charger topologies, charging power levels, and infrastructure for plug-in electric and hybrid vehicles. IEEE Trans. Power Electron. 2013, 28, 2151-2169. [CrossRef]

6. Emadi, A.; Lee, Y.J.; Rajashekara, K. Power electronics and motor drives in electric, hybrid electric, and plug-in hybrid electric vehicles. IEEE Trans. Ind. Electron. 2008, 55, 2237-2245. [CrossRef]

7. Chan, C.C.; Chau, K.T. An overview of power electronics in electric vehicles. IEEE Trans. Ind. Electron. 1997, 44, 3-13. [CrossRef]

8. Mishimay, T.; Hiraki, E.; Nakaoka, M. A High Frequency-Link Bidirectional DC-DC Converter for Super Capacitor-Based Automotive Auxiliary Electric Power Systems. J. Power Electron. 2010, 10, 27-33. [CrossRef]

9. Krismer, F.; Biela, J.; Kolar, J.W. A Comparative Evaluation of Isolated Bi-directional DC/DC Converters with Wide Input and Output Voltage Range. In Proceedings of the Conference Record of the 2005 Industry Applications Conference, Hong Kong, China, 2-6 October 2005; pp. 599-606.

10. Lee, J.Y.; Jeong, Y.S.; Han, B.M. A two-stage isolated/bidirectional DC/DC converter with current ripple reduction technique. IEEE Trans. Ind. Electron. 2012, 59, 644-646. [CrossRef]

11. Zhang, Y.; Gao, Y.; Li, J.; Sumner, M. Interleaved switched-capacitor bidirectional dc-dc converter with wide voltage-gain range for energy storage systems. IEEE Trans. Power Electron. 2018, 33, 3852-3869. [CrossRef]

12. Mangu, B.; Akshatha, S.; Suryanarayana, D.; Fernandes, B.G. Grid-connected PV-wind-battery-based multi-input transformer-couple bidirectional dc-dc converter for household applications. IEEE J. Emerg. Sel. Top. Power Electron. 2016, 4, 1086-1095. [CrossRef]

13. Shen, C.L.; Shen, Y.S.; Chiu, P.C.; Liang, T.C. Isolated bidirectional converter with minimum active switches for high-voltage ratio achievement and micro-grid applications. IET Proc. Power Electron. 2017, 10, 2208-2216. [CrossRef]

14. Pledl, G.; Tauer, M.; Buecherl, D. Theory of operation, design procedure and simulation of a bidirectional LLC resonant converter for vehicular applications. In Proceedings of the 2010 IEEE Vehicle Power and Propulsion Conference, Lille, France, 1-3 September 2010; pp. 1-5.

15. Tan, K.; Yu, R.; Guo, S.; Huang, A.Q. Optimal design methodology of bidirectional LLC resonant DC/DC converter for solid state transformer application. In Proceedings of the IECON 2014-40th Annual Conference of the IEEE Industrial Electronics Society, Dallas, TX, USA, 29 October-1 November 2014; pp. 1657-1664.

16. Kim, E.S.; Park, J.H.; Jeon, Y.S.; Kong, Y.S.; Lee, S.M.; Kim, K. Bidirectional secondary LLC resonant converter using auxiliary switches and inductor. In Proceedings of the 2014 IEEE Applied Power Electronics Conference and Exposition (APEC 2014), Fort Worth, TX, USA, 16-20 March 2014; pp. 1941-1947.

17. Jiang, T.; Zhang, J.; Wu, X.; Sheng, K.; Wang, Y. A bidirectional LLC resonant Converter with automatic forward and backward mode transition. IEEE Trans. Power Electron. 2015, 30, 757-770. [CrossRef]

18. Lin, B.R.; Chu, C.W. DC/DC converter with parallel input and parallel output with shared power switches and rectifier diodes. IET Proc. Power Electron. 2015, 8, 814-821. [CrossRef]

19. Matko, V.; Milanović, M. Temperature-compensated capacitance-frequency converter with high resolution. Sens. Actuators A Phys. 2014, 220, 262-269. [CrossRef]

20. Azevedo, R.G.; Huang, W.; O’Reilly, O.M.; Pisano, A.P. Dual-mode temperature compensation for a comb-driven MEMS resonant strain gauge. Sens. Actuators A Phys. 2008, 144, 374-380. [CrossRef]

21. Matko, V. Next generation AT-cut quartz crystal sensing devices. Sensors 2011, 11, 4474-4482. [CrossRef] [PubMed]

22. Steigerwald, R. A comparison of half bridge resonant converter topologies. IEEE Trans. Power Electron. 1988, 3, 135-144. [CrossRef]

(C) 2018 by the authors. Licensee MDPI, Basel, Switzerland. This article is an open access article distributed under the terms and conditions of the Creative Commons Attribution (CC BY) license (http:/ / creativecommons.org/licenses/by/4.0/). 